\title{
Effects of prime and target eccentricity on masked repetition priming
}

\author{
YousRi Marzouki ANd Jonathan Grainger \\ CNRS and Aix-Marseille University, Marseille, France
}

\begin{abstract}
Three experiments examined the influence of briefly presented, pattern-masked prime stimuli on target word recognition at varying eccentricities. The prime was either the same word as the targets or a different word, and prime position varied horizontally from a central fixation point. The targets were either in the same location as the primes (Experiment 1A) or always centrally located (Experiments 1B and 2). In Experiment 1A, target word recognition showed a typical right visual field advantage, and priming effects diminished with increasing prime and target eccentricity. With centrally located targets, priming effects tended to be more constrained by prime location. After eye fixation location and prime visibility were controlled for (Experiment 2), a right visual field advantage for priming effects was also evident for central targets, suggesting an influence of endogenous attentional biases in masked repetition priming.
\end{abstract}

In normal reading, information about the word immediately following the currently fixated word is available before the reader's eyes fixate that word. This has been clearly shown using parafoveal priming techniques and varying the nature of the relation between the parafoveal stimulus and the target word. These studies have shown that the processing of the upcoming target word in the parafovea is facilitated when the parafoveal preview is orthographically and/or phonologically similar to that word (e.g., Pollatsek, Lesch, Morris, \& Rayner, 1992; Rayner, 1998).

Most relevant for the present experiments are the seminal studies of Rayner, McConkie, and Ehrlich (1978) and Rayner, McConkie, and Zola (1980). These authors examined parafoveal priming effects with primes of varying eccentricity and targets that appeared either centrally (with no eye movement) or at the same location as the parafoveal prime stimulus (so that the targets were foveated following an appropriate eye movement). The results showed a strong influence of prime eccentricity on the size of priming effects, with more eccentric primes generating smaller effects. On the other hand, priming effects did not depend on whether the target word was centrally located or not. In other words, priming did not depend on whether or not the target appeared at the same location as the prime, hence suggesting that the bulk of the priming effect was carried by location-invariant lexical and sublexical representations. However, the pattern of priming effects reported by Rayner et al. (1978; Rayner et al., 1980) could be due to the relatively long prime exposures used in these studies (around $190 \mathrm{msec}$, approximating the durations typical of parafoveal previews in normal reading). Also, the participants were required to make either vocal (naming task) or manual (semantic categorization task) responses, and there was a large amount of target repetition. In these testing conditions, it is likely that the observed effects reflect both the automatic uptake of perceptual information from primes (a process that might well be location specific) and some form of strategic processing. The latter type of process would not be location specific and could, therefore, be the source of priming effects obtained when targets appeared centrally.

One way to reduce contamination from such strategic factors is to use the masked-priming paradigm (Forster \& Davis, 1984). Robust masked repetition priming effects with horizontally displaced peripheral primes and central targets were reported by Marzouki, Grainger, and Theeuwes (2007). This study used isolated letter stimuli and varied the amount of attention directed to the subliminally presented peripheral primes by manipulating the presence of an abrupt onset cue just prior to the prime stimulus, in either the same location as the prime or a different location. However, significant repetition priming was found only in the presence of a valid exogenous cue. Similarly, masked repetition priming effects with word stimuli have been reported by Lachter, Forster, and Ruthruff (2004) with vertically displaced prime stimuli-again, only when the primes were preceded by a valid spatial cue (see also Besner, Risko, \& Sklair, 2005). Therefore, with brief stimulus presentation (typically, 50-60 msec) and pattern-masking procedures, the evidence at present suggests that peripheral primes do not influence the subsequent processing of centrally located targets unless attention is attracted to the prime location.

The present study provides a further investigation of masked repetition priming with horizontally displaced prime stimuli, while adding a parametric manipulation of prime eccentricity and a manipulation of target location (central or peripheral). In Experiment 1, prime and target

Y. Marzouki, yousri.marzouki@univ-provence.fr 
stimuli appeared at the same location at varying eccentricities (see Figure 1). In Experiment 1A, targets appeared at varying eccentricities in the same location as primes, and in Experiment 1B, targets always appeared centrally. Experiment 2 controlled for eye movements, eye fixation location, and prime visibility in the same testing conditions as those in Experiment 1B.

\section{EXPERIMENT 1}

\section{Method}

\section{Participants}

Fifty-six participants ( 19 of them male, mean age $=22$ years), all right-handed native French speakers, volunteered to participate in the experiment. All the participants reported normal or correctedto-normal vision. Twenty-one participated in Experiment 1A, and 35 in Experiment 1B.

\section{Design and Stimuli}

One hundred five French five-letter words and 105 pronounceable five-letter pseudowords served as targets. Each target was preceded either by the same word/pseudoword or by a different word/pseudoword, defining the two levels of the repetition factor. The prime and target stimuli could appear at seven different positions along the horizontal meridian spanning the central fixation point (see Figure 1). These positions defined the seven levels of the eccentricity factor and varied from $-6^{\circ}$ (extreme left) to $+6^{\circ}$ (extreme right). In Experiment 1A, the prime and target stimuli always appeared at the same location, whereas in Experiment 1B, the prime position was manipulated (see Figure 1) and the targets always appeared centrally. Eccentricity was crossed with repetition in a $7 \times 2$ factorial design. Standard counterbalancing with a Latin square allowed each target to be tested at each of the seven levels of eccentricity across participants, with each participant receiving 30 different items (15 words and 15 pseudowords) at each eccentricity level. Each word/pseudoword target was seen twice by each participant, once in the repetition prime condition and once with an unrelated prime.

\section{Procedure}

The experiment was run inside a dimly lit room and was controlled using DMDX software (Forster \& Forster, 2003). The participants were seated in front of a computer screen on which stimuli were displayed in white on a black background in VGA mode (75-Hz refresh). The background luminance of the screen was approximately $1 \mathrm{~cd} / \mathrm{m}^{2}$, and stimulus luminance was approximately $92 \mathrm{~cd} / \mathrm{m}^{2}$. The procedure is described in Figure 1. Each trial began with a forward mask for $500 \mathrm{msec}$, formed of a string of hash marks with two vertical bars (I) placed above and below the center. Prime stimuli appeared immediately after this for a duration of $60 \mathrm{msec}$ and were followed by a backward mask (a string of hash marks the same length as the forward mask) lasting $12 \mathrm{msec}$, which, in turn, was replaced by the target stimulus, which remained on the screen until the participants' response. The prime and target stimuli were presented in 14-point bold courier new font with each letter subtending $0.9^{\circ}$ of visual angle. The width of each letter was $0.4 \mathrm{~cm}$, and the height was $0.5 \mathrm{~cm}$. The reported visual angles for each level of eccentricity defined the distance between the central fixation location and the center of the stimulus at a viewing distance of $80 \mathrm{~cm}$. The participants were asked to respond as rapidly and as accurately as possible by pressing one of two triggers of a Microsoft SideWinder game pad with their index fingers: right button for words and left button for pseudowords. The participants first performed a practice session with a set of 15 words and pseudowords that did not appear in the main experiment, followed by the 420 trials of the main experiment in random order. The participants were tested in either Experiment 1A or 1B in a session lasting approximately $30 \mathrm{~min}$.

\section{Results}

Reaction times (RTs) lying outside of the mean plus or minus two standard deviations were removed before analysis (7\% for Experiment $1 \mathrm{~A}$ and $8.6 \%$ for Experi-

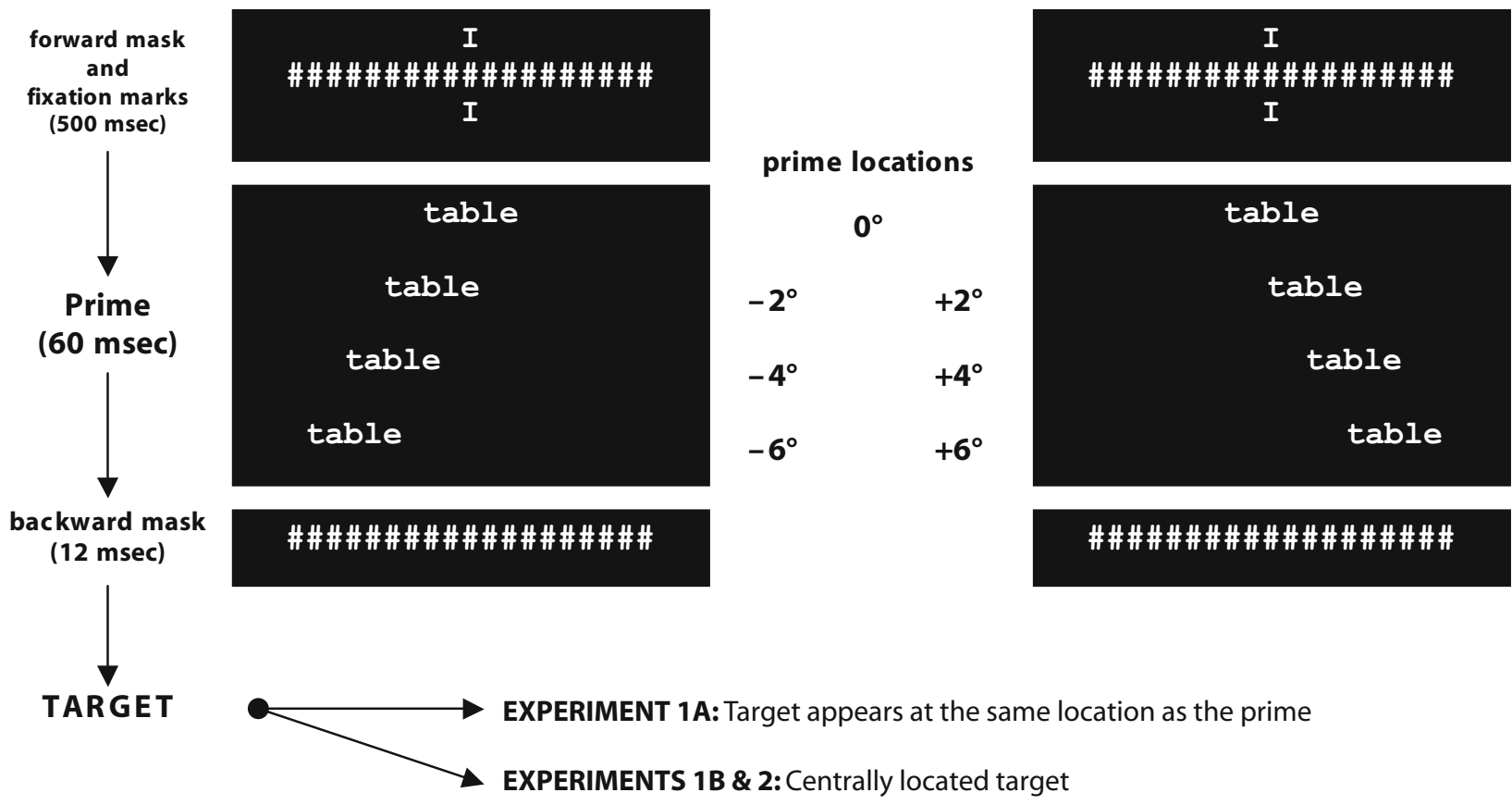

Figure 1. Experimental procedure used in the present study. Prime stimuli occupied seven possible positions $\left(\right.$ from $-6^{\circ}$ to $\left.+6^{\circ}\right)$ defining seven levels of prime eccentricity. The eccentricity values (degrees of visual angle) represent the distance from fixation center of the prime stimulus. The distance from fixation to the initial/final letter of prime stimuli at the three eccentric locations was $0^{\circ}, 2^{\circ}$, or $4^{\circ}$. 
Table 1

Mean Reaction Times (RTs, in Milliseconds) and Percentages of Errors (\% Errors) Plus or Minus Standard Errors of the Means for Word Targets in Experiment 1 (A, Peripheral Targets; B, Central Targets)

\begin{tabular}{|c|c|c|c|c|}
\hline \multirow{2}{*}{$\begin{array}{c}\text { Level of } \\
\text { Eccentricity }\end{array}$} & \multicolumn{2}{|c|}{ Experiment 1A } & \multicolumn{2}{|c|}{ Experiment 1B } \\
\hline & Repeat & Unrelated & Repeat & Unrelated \\
\hline \multicolumn{5}{|l|}{$-6^{\circ}$} \\
\hline Mean RT & $748 \pm 9.6$ & $756.6 \pm 11.8$ & $659.3 \pm 14.8$ & $667.8 \pm 14$ \\
\hline$\%$ error & $5.1 \pm 1.5$ & $6.7 \pm 1.7$ & $5.3 \pm 1.4$ & $4.2 \pm 1$ \\
\hline \multicolumn{5}{|l|}{$-4^{\circ}$} \\
\hline Mean RT & $703 \pm 11.1$ & $725.8 \pm 8.4$ & $660.9 \pm 15.5$ & $674.6 \pm 15.9$ \\
\hline$\%$ error & $6.0 \pm 1.7$ & $6.7 \pm 1.7$ & $7.8 \pm 1.5$ & $6.1 \pm 1.3$ \\
\hline \multicolumn{5}{|l|}{$-2^{\circ}$} \\
\hline Mean RT & $651 \pm 12.1$ & $691.7 \pm 8.9$ & $640.1 \pm 13.9$ & $678.2 \pm 15.3$ \\
\hline$\%$ error & $4.8 \pm 1.5$ & $5.7 \pm 1.5$ & $6.3 \pm 1.2$ & $6.3 \pm 1.2$ \\
\hline \multicolumn{5}{|l|}{$0^{\circ}$} \\
\hline Mean RT & $621.1 \pm 13.6$ & $669.5 \pm 11.3$ & $614.4 \pm 16.1$ & $672.7 \pm 13.9$ \\
\hline$\%$ error & $3.8 \pm 1$ & $3.5 \pm 1.4$ & $4.8 \pm 1$ & $5.5 \pm 1.5$ \\
\hline \multicolumn{5}{|l|}{$+\mathbf{2}^{\mathbf{o}}$} \\
\hline Mean RT & $624.4 \pm 10.2$ & $695.8 \pm 8.8$ & $626 \pm 16.3$ & $674.6 \pm 13.9$ \\
\hline$\%$ error & $4.4 \pm 1.1$ & $3.8 \pm 1$ & $3.4 \pm 1$ & $5.7 \pm 0.9$ \\
\hline \multicolumn{5}{|l|}{$+4^{\circ}$} \\
\hline Mean RT & $674.4 \pm 13.6$ & $699.7 \pm 9.2$ & $660.9 \pm 14.9$ & $669 \pm 13.1$ \\
\hline$\%$ error & $4.4 \pm 1.2$ & $3.5 \pm 1$ & $4.2 \pm 1.2$ & $5.3 \pm 1.4$ \\
\hline \multicolumn{5}{|l|}{$+6^{\circ}$} \\
\hline Mean RT & $699.5 \pm 12.3$ & $728.8 \pm 10.4$ & $656.1 \pm 16.3$ & $663.4 \pm 12.9$ \\
\hline$\%$ error & $4.8 \pm 1$ & $2.9 \pm 1$ & $4.8 \pm 1.1$ & $5.3 \pm 1.4$ \\
\hline
\end{tabular}

ment 1B). Table 1 provides average correct RTs and percentages of errors for words, and Table 2 the results for pseudowords in each experimental condition. The results of each experiment will be presented separately before the results of a combined analysis are described.

\section{Experiment 1A}

Word analyses. Eccentricity $\left(-6^{\circ},-4^{\circ},-2^{\circ}, 0^{\circ},+2^{\circ}\right.$, $+4^{\circ}$, and $\left.+6^{\circ}\right)$ and repetition were entered into a repeated measures ANOVA. There were significant main effects of eccentricity $\left[F(6,120)=45.93, M S_{\mathrm{e}}=1,263.71, p<\right.$ $.0001]$ and repetition $\left[F(1,20)=57.74, M S_{\mathrm{e}}=1,571.45\right.$, $p<.0001]$ and a significant interaction $[F(6,120)=4.94$, $\left.M S_{\mathrm{e}}=894.79, p<.0005\right]$. As can be seen in Figure 2, repetition priming diminished with increasing eccentricity. There were no main effects and no interaction in the ANOVA for the accuracy data.

Pseudoword analyses. Analyses on RTs revealed reliable main effects of eccentricity $[F(6,120)=22.98$, $\left.M S_{\mathrm{e}}=1,609.51, p<.0001\right]$ and repetition $[F(1,20)=$

Table 2

Mean Reaction Times (RTs, in Milliseconds) and Percentages of Errors (\% Errors) Plus or Minus Standard Errors of the Means for Pseudoword Targets in Experiments 1 and 2

\begin{tabular}{|c|c|c|c|c|c|c|}
\hline \multirow{2}{*}{$\begin{array}{c}\text { Level of } \\
\text { Eccentricity }\end{array}$} & \multicolumn{2}{|c|}{ Experiment 1A } & \multicolumn{2}{|c|}{ Experiment 1B } & \multicolumn{2}{|c|}{ Experiment 2} \\
\hline & Repeat & Unrelated & Repeat & Unrelated & Repeat & Unrelated \\
\hline \multicolumn{7}{|l|}{$-6^{\circ}$} \\
\hline Mean RT & $840.8 \pm 15.0$ & $858.4 \pm 16.4$ & $736.8 \pm 20.1$ & $765.0 \pm 20.7$ & $662.6 \pm 11.6$ & $666.8+12.2$ \\
\hline \% error & $4.4 \pm 1.8$ & $3.2 \pm 1.0$ & $3.92 \pm 1.0$ & $7.65 \pm 1.5$ & $4.3 \pm 1.1$ & $5.3 \pm 1.6$ \\
\hline \multicolumn{7}{|l|}{$-4^{\circ}$} \\
\hline Mean RT & $815.7 \pm 14.8$ & $836.8 \pm 17.3$ & $750.2 \pm 20.4$ & $756.1 \pm 21.7$ & $654.6 \pm 11.8$ & $668.4 \pm 10.9$ \\
\hline$\%$ error & $2.9 \pm 1.0$ & $3.5 \pm 0.9$ & $4.12 \pm 1.0$ & $7.45 \pm 1.4$ & $6.3 \pm 1.6$ & $5.3 \pm 1.2$ \\
\hline \multicolumn{7}{|l|}{$-2^{\circ}$} \\
\hline Mean RT & $772.9 \pm 16.3$ & $801.7 \pm 14.2$ & $724.9 \pm 16.9$ & $763.6 \pm 18.6$ & $641.8 \pm 12.1$ & $663.7 \pm 11.4$ \\
\hline $\begin{array}{l}\% \text { error } \\
0^{\mathbf{0}}\end{array}$ & $2.2 \pm 0.8$ & $4.8 \pm 1.6$ & $6.27 \pm 1.4$ & $4.9 \pm 1.0$ & $4.5 \pm 1.0$ & $5.7 \pm 1.4$ \\
\hline Mean RT & $737.8 \pm 15.9$ & $796.3 \pm 14.7$ & $706.7 \pm 21.3$ & $781.2 \pm 20.3$ & $619.6 \pm 12.8$ & $672.7 \pm 10.8$ \\
\hline$\%$ error & $4.8 \pm 1.4$ & $3.2 \pm 1.0$ & $5.29 \pm 1.2$ & $6.86 \pm 1.1$ & $6.5 \pm 1.6$ & $6.7 \pm 1.5$ \\
\hline \multicolumn{7}{|l|}{$+2^{\circ}$} \\
\hline Mean RT & $767.9 \pm 18.8$ & $806.8 \pm 14.7$ & $735.7 \pm 19.6$ & $766.0 \pm 20.5$ & $632.7 \pm 12.2$ & $658.1 \pm 11.8$ \\
\hline$\%$ error & $3.5 \pm 1.1$ & $4.8 \pm 1.6$ & $4.71 \pm 1$ & $4.9 \pm 1.1$ & $6.1 \pm 1.0$ & $7.3 \pm 1.2$ \\
\hline \multicolumn{7}{|l|}{$+4^{\circ}$} \\
\hline Mean RT & $799.2 \pm 19.5$ & $831 \pm 20.0$ & $736.2 \pm 20.0$ & $756.2 \pm 19.2$ & $649.9 \pm 12.0$ & $660.4 \pm 12.1$ \\
\hline$\%$ error & $5.4 \pm 1.3$ & $3.8 \pm 1.1$ & $4.12 \pm 1$ & $6.47 \pm 1.2$ & $5.1 \pm 1.3$ & $4.9 \pm 1.3$ \\
\hline \multicolumn{7}{|l|}{$+6^{\circ}$} \\
\hline Mean RT & $826.6 \pm 16.8$ & $840.5 \pm 16.8$ & $750.6 \pm 21.4$ & $758.6 \pm 21.4$ & $665.0 \pm 10.8$ & $656.8 \pm 10.7$ \\
\hline$\%$ error & $5.7 \pm 1.3$ & $3.8 \pm 1.1$ & $4.71 \pm 0.9$ & $4.51 \pm 0.9$ & $4.1 \pm 0.8$ & $5.1 \pm 1.2$ \\
\hline
\end{tabular}


$\left.80.20, M S_{\mathrm{e}}=829.15, p<.0001\right]$ but no interaction $\left[F(6,120)=2.03, M S_{\mathrm{e}}=1,201.09, p>.05\right]$. There were no significant effects in the accuracy data (see Table 2 ).

\section{Experiment 1B}

Word analyses. A repeated measures ANOVA was performed with the same design as that in Experiment $1 \mathrm{~A}$. RTs increased with increasing eccentricity $[F(6,204)=$ $\left.5.21, M S_{\mathrm{e}}=995.68, p<.0001\right]$ and were shorter following a repetition prime, as compared with unrelated primes $\left[F(1,34)=96.62, M S_{\mathrm{e}}=864.13, p<.00001\right]$. Repetition priming interacted with eccentricity $[F(6,204)=9.58$, $\left.M S_{\mathrm{e}}=860.98, p<.0001\right]$, with priming effects decreasing as prime eccentricity increased (see Figure 2) There were no significant main effects and no interaction in the ANOVA performed on the accuracy data.

Pseudoword analyses. Analyses on RTs showed a significant effect of repetition $\left[F(1,34)=65.49, M S_{\mathrm{e}}=\right.$ $1,613.0, p<.0001]$ and a significant interaction with eccentricity $\left[F(6,204)=7.25, M S_{\mathrm{e}}=1,299.10, p<.0001\right]$. In the accuracy data, there was a reliable main effect of repetition $\left[F(1,34)=9.22, M S_{\mathrm{e}}=0.60, p<.005\right]$ and a significant interaction $\left[F(6,120)=2.55, M S_{\mathrm{e}}=0.54\right.$, $p<.05]$.

\section{Combined Analysis of Experiments 1A and 1B}

In this analysis, the variable experiment (Experiment $1 \mathrm{~A}$ vs. Experiment 1B) was introduced as a betweenparticipants factor. The result of the mixed ANOVA showed significant effects of eccentricity $[F(6,324)=$ $\left.46.55, M S_{\mathrm{e}}=50,970.45, p<.0001\right]$ and prime relatedness $\left[F(1,54)=153, M S_{\mathrm{e}}=172,289.09, p<.0001\right]$ and no effect of experiment $\left[F(1,54)=3.07, M S_{\mathrm{e}}=2,087,740.61\right.$, $p<.1]$. Furthermore, the ANOVA revealed reliable twoway interactions between experiment and eccentricity $\left[F(6,324)=23.26, M S_{\mathrm{e}}=25,473.09, p<.0001\right]$ and between eccentricity and prime relatedness $[F(6,324)=$ 12.27, $\left.M S_{\mathrm{e}}=10,716.31, p<.0001\right]$. Figure 2 shows that the interaction between eccentricity and experiment was driven mostly by the unrelated prime condition, given that eccentricity was manipulated only on the prime stimuli in Experiment 1B. The interaction between eccentricity and relatedness reflects the fact that priming effects diminished with increasing prime eccentricity. The critical interaction between experiment and relatedness was only marginally significant $\left[F(1,54)=3.33, M S_{\mathrm{e}}=3,744.67\right.$, $p<.1]$, and there was no triple interaction $[F(6,324)=$ $\left.1.14, M S_{\mathrm{e}}=993.69, p>.1\right]$.

An additional ANOVA examined the effects of visual hemifield on RTs to word targets in the following repeated measures design (with the central position omitted): visual field (left vs. right) $\times$ eccentricity (distal, medial, and proximal to fixation) $\times$ repetition (repeated vs. unrelated) $\times$ experiment (Experiment $1 \mathrm{~A}$ vs. Experiment $1 \mathrm{~B})$. The effect of visual field was significant $\left[F(1,54)=25.21, M S_{\mathrm{e}}=1,478.18, p<.0001\right]$, and this factor interacted with experiment $[F(1,54)=11.18$, $\left.M S_{\mathrm{e}}=1,478.18, p<.001\right]$, but not with eccentricity $\left[F(2,108)=1.38, M S_{\mathrm{e}}=1,154.82, p>.1\right]$. There was
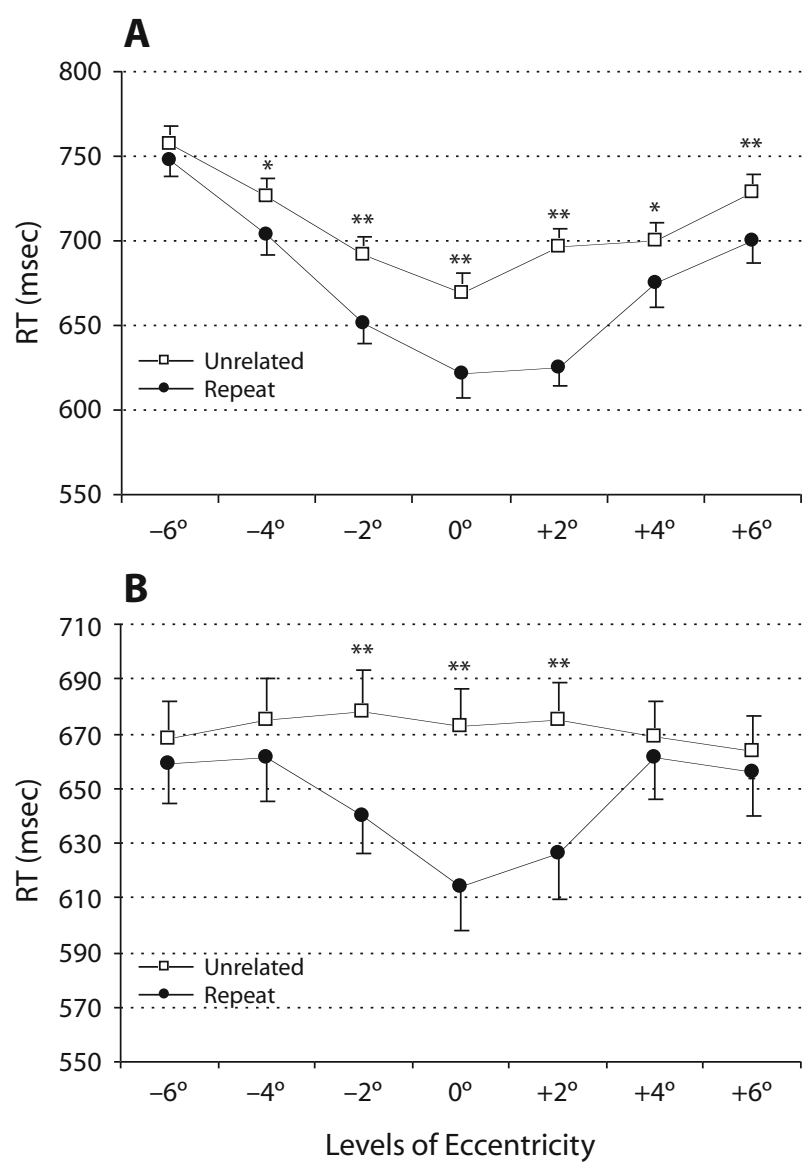

Figure 2. Interaction between priming and eccentricity in Experiment $1 \mathrm{~A}$ (A; prime and target appeared at the same location) and in Experiment 1B (B; peripheral primes and central targets). Significant priming effects for a given level of eccentricity are indicated by asterisks. ${ }^{*} p<.05 .{ }^{* *} p<.01$.

a marginally significant interaction between visual field and prime relatedness $\left[F(1,54)=3.00, M S_{\mathrm{e}}=1,218.28\right.$, $p<.1$, reflecting the fact that priming effects were numerically larger in the right visual field (RVF). There was a significant interaction between experiment and prime relatedness $\left[F(1,54)=6.38, M S_{\mathrm{e}}=918.78, p<.01\right]$, with stronger priming effects in Experiment $1 \mathrm{~A}$ (peripheral targets) than in Experiment $1 \mathrm{~B}$ (central targets). The three- and four-way interactions were not significant.

\section{EXPERIMENT 2}

Experiment 1 showed repetition priming that varied as a function of prime eccentricity and target location. Priming effects were strongest with the most centrally located primes and tended to be stronger with peripherally located targets (Experiment 1A), relative to centrally located targets (Experiment 1B). It is possible that some of the priming effects obtained at noncentral prime locations in Experiment 1 could have been due to eye movements triggered upon prime presentation and/or initial noncentral eye fixations. Experiment 2 investigated this possibility for the central target 
location condition of Experiment 1B and also included a measure of prime visibility in these testing conditions.

\section{Method}

\section{Participants}

Thirty-four participants ( 12 of them male, mean age $=22$ years), all right-handed native French speakers, were paid to participate in this experiment. All the participants reported normal or correctedto-normal vision.

\section{Design and Stimuli}

The design and stimuli were the same as those in Experiment 1B.

\section{Procedure}

The experiment was run inside a dimly lit room. The stimuli were displayed on a computer screen in VGA mode (75-Hz refresh), using E-Prime 1.1 software. The background luminance of the screen was $0.01 \mathrm{~cd} / \mathrm{m}^{2}$, and stimulus luminance was $5.98 \mathrm{~cd} / \mathrm{m}^{2}$. Eye movements were recorded during the experiment with a video-based eye tracker, iView X 1.05 Remote Eyetracking Device. An infrared video-based camera was used to track the pupil position, the pupil diameter, and the gaze position of the right eye. Before eye movements were recorded, a calibration test was performed in which the participants were instructed to follow the movement of a yellow dot on a blue screen. Viewing distance was held constant at $80 \mathrm{~cm}$ with a chin-/headrest. Eye position was sampled every $4 \mathrm{msec}$ and was analyzed offline with customized software. Otherwise, the procedure for the main experiment was identical to that in Experiment 1B (see Figure 1). After the main experiment, each participant received a further 210 trials using the same stimuli as those in the main experiment. The target stimulus was always a word, and primes could be words (on $50 \%$ of the trials) or pseudowords appearing randomly at each eccentricity level. Each word target was seen twice by each participant, once primed by a different word and once primed by a pseudoword. After the participants had been informed of the presence of prime stimuli, they were instructed to perform a two-alternative forced choice task in which they decided whether the prime was a word or a pseudoword on every trial. The main experiment plus the visibility test lasted approximately $45 \mathrm{~min}$.

\section{Results}

Mean RTs and percentages of errors per experimental condition are given in Table 3 for word targets and in Table 2 for pseudoword targets. Prior to the removal of trials on which an eye movement occurred and trials with noncentral fixation locations, an initial analysis of the RT data in Experiment 2 (using the same data-trimming procedure as that in Experiment 1 with $4.3 \%$ of rejected trials) revealed a replication of the pattern found in Experiment 1B. There were significant main effects of eccentricity $\left[F(6,198)=16.28, M S_{\mathrm{e}}=746.28, p<.0001\right]$ and repetition $\left[F(1,33)=154.91, M S_{\mathrm{e}}=606.68, p<.0001\right]$ and a significant interaction $\left[F(6,198)=11.29, M S_{\mathrm{e}}=\right.$ $722.41, p<.0001]$. In an analysis of the data for pseudoword targets, there were significant main effects of eccentricity $\left[F(6,198)=4.94, M S_{\mathrm{e}}=793.38, p<.0001\right]$ and repetition $\left[F(1,33)=57.63, M S_{\mathrm{e}}=614.69, p<.0001\right]$ and a significant interaction $\left[F(6,198)=10.17, M S_{\mathrm{e}}=\right.$ $627.63, p<.0001]$. There were no main effects and no interaction in the accuracy data for pseudowords $(F<1)$.

\section{Eye Movement Analysis}

Prior to analysis, we eliminated all trials on which eye movements were detected. We also eliminated all trials on which eye fixation during prime presentation was outside of a central zone, defined as \pm 1 letter from the center of the display. This acceptance criterion corresponds to a pixel interval on the $x$-axis equal to (482, 542) (see Figure 3). After trials had been removed using these criteria, 4 participants were excluded because of a

Table 3

Mean Reaction Times (RTs, in Milliseconds) and Percentages of Errors (\% Errors) Plus or Minus Standard Errors of the Means for Word Targets in Experiment 2

\begin{tabular}{|c|c|c|c|c|}
\hline \multirow{2}{*}{$\begin{array}{c}\text { Level of } \\
\text { Eccentricity }\end{array}$} & \multicolumn{2}{|c|}{$\begin{array}{c}\text { Experiment } 2 \\
\text { (All Participants and Trials) }\end{array}$} & \multicolumn{2}{|c|}{$\begin{array}{l}\text { Experiment } 2 \\
\text { (Without Eye Movements and } \\
\text { With Low Prime Visibility) }\end{array}$} \\
\hline & Repeat & Unrelated & Repeat & Unrelated \\
\hline \multicolumn{5}{|l|}{$-6^{0}$} \\
\hline Mean RT & $604.4 \pm 9.9$ & $612.3 \pm 9.5$ & $624.8 \pm 10.3$ & $649.4 \pm 11.8$ \\
\hline$\%$ err & $10.0 \pm 1.5$ & $6.1 \pm 1.5$ & $8.8 \pm 1.7$ & $6.4 \pm 1.8$ \\
\hline \multicolumn{5}{|l|}{$-4^{\circ}$} \\
\hline Mean RT & $599.2 \pm 9.5$ & $610.6 \pm 10.9$ & $633.7 \pm 11.7$ & $636.4 \pm 12.5$ \\
\hline \% error & $10.4 \pm 1.4$ & \multirow{2}{*}{\multicolumn{3}{|c|}{$-2^{\circ}$}} \\
\hline Mean RT & $575.0 \pm 12.6$ & & & \\
\hline $\begin{array}{l}\% \text { error } \\
\mathbf{0}^{\mathbf{0}}\end{array}$ & $10.0 \pm 1.4$ & $69+12$ & $9.6 \pm 1.8$ & $6.1 \pm 1.4$ \\
\hline Mean RT & $546.1 \pm 13.1$ & $603.4 \pm 10.2$ & $568.5 \pm 11.3$ & $626.1 \pm 9.7$ \\
\hline$\% \mathrm{e}$ & $5.7 \pm 1.3$ & $5.7 \pm 1.1$ & $6.9 \pm 1$ & $6.7 \pm 1.3$ \\
\hline \multicolumn{5}{|l|}{$+2^{\circ}$} \\
\hline Mean RT & $551.8 \pm 12.5$ & $609.3 \pm 11.4$ & $591.8 \pm 14.5$ & $653.4 \pm 11.7$ \\
\hline \% error & $6.1 \pm 1.0$ & $9.4 \pm 1.5$ & $5.9 \pm 1$ & $9.9 \pm 1.9$ \\
\hline \multicolumn{5}{|l|}{$+4^{\circ}$} \\
\hline Mean RT & $582.2 \pm 12.5$ & $611.6 \pm 10.5$ & $628.8 \pm 13.3$ & $648.3 \pm 12.3$ \\
\hline$\%$ er & $5.9 \pm 1.2$ & & $6.4 \pm 1.4$ & $8.5 \pm 1.6$ \\
\hline \multicolumn{5}{|l|}{$+6^{\circ}$} \\
\hline Mean RT & $608.7 \pm 8.5$ & $613.1 \pm 11.9$ & $617.7 \pm 13.3$ & $648.3 \pm 12.3$ \\
\hline$\%$ error & $9.2 \pm 1.4$ & $7.8 \pm 1.7$ & $9.9 \pm 1.7$ & $7.7 \pm 2.2$ \\
\hline
\end{tabular}




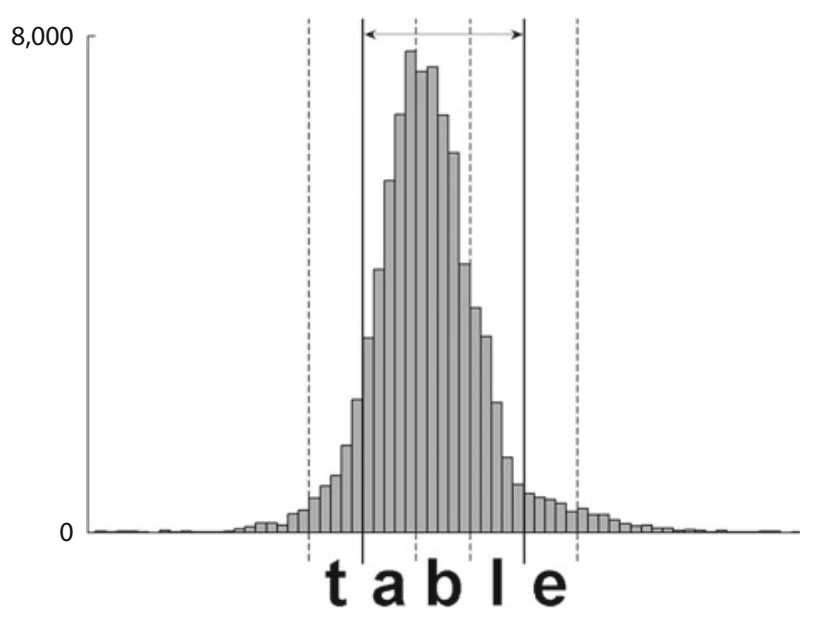

Figure 3. Distributions of eye fixation location along the horizontal axis during the presentation of prime words after excluding participants with excessive eye movements $(n=30)$. The double arrow delimits the central fixation zone $( \pm 1$ letter from the central letter in foveal position $0^{\circ}$ ) used to exclude trials with noncentral fixations. The distribution is left biased, with $60.3 \%$ of rejected trials to the left and $39.7 \%$ to the right.

high rejection rate $(M=95.2 \%)$. For the remaining 30 participants, the mean percentage of rejected trials was $14.7 \%$. An ANOVA on the RT data with words following artifact rejection revealed reliable main effects of eccentricity $\left[F(6,174)=9.78, M S_{\mathrm{e}}=1,651.76, p<.0001\right]$ and repetition $\left[F(1,29)=93.72, M S_{\mathrm{e}}=1,478.29, p<.0001\right]$, and a significant interaction $\left[F(6,174)=3.61, M S_{\mathrm{e}}=\right.$ $1,603.71, p<.005]$.

As in Experiment 1, we examined the effects of visual field by omitting the central fixation position. There were main effects of eccentricity $\left[F(2,58)=5.07, M S_{\mathrm{e}}=\right.$ $1,736.11, p<.01]$ and repetition, $F(1,29)=58.72, M S_{\mathrm{e}}=$ $1,596.55, p<.0001]$ and no main effect of visual field $(F<1)$. Visual field significantly interact with repetition $\left[F(1,29)=8.37, M S_{\mathrm{e}}=1,619.53, p<.001\right]$, revealing stronger priming in the $\operatorname{RVF}\left[F(1,29)=56.01, M S_{\mathrm{e}}=\right.$ $1,594.23, p<.0001]$ than in the left visual field (LVF) $\left[F(1,29)=11.10, M S_{\mathrm{e}}=1,621.85, p<.005\right]$. The other two-way interactions and the three-way interaction were not significant.

\section{Visibility Test Analysis}

An overall estimation of prime visibility $\left(d^{\prime}\right)$ was calculated per participant, using the proportions of hits and false alarms in the visibility test. Comparison of the $d^{\prime}$ values for the 30 participants against chance performance (zero) showed a significant difference $[M=0.13, S D=$ $0.22 ; t(29)=3.31, p<.005]$. In order to remove participants with the highest level of prime visibility, $d^{\prime}$ values were ranked in descending order, and successive $t$ tests were performed, removing participants until the test was not significant. This led to the removal of 5 participants, thus leaving 25 participants whose prime visibility level did not differ significantly from chance $[M=0.06, S D=$ $0.16 ; t(24)=1.93, p>.05]$.
An ANOVA on the RT data following artifact rejection (eye movements) and including only participants with the lowest level of prime visibility $(n=25)$ showed significant main effects of eccentricity $\left[F(6,144)=7.22, M S_{\mathrm{e}}=\right.$ $1,475.99, p<.0001]$ and repetition $[F(1,24)=73.30$, $\left.M S_{\mathrm{e}}=1,248.85, p<.0001\right]$ and a significant interaction $\left[F(6,144)=3.91, M S_{\mathrm{e}}=1,429.17, p<.005\right]$. After omitting the central position, the analysis including visual field as a factor showed a reliable interaction between visual field and repetition $\left[F(1,24)=4.86, M S_{\mathrm{e}}=1,854.21\right.$, $p<.05]$, with stronger priming effects for primes in the $\operatorname{RVF}\left[F(1,24)=37.78, M S_{\mathrm{e}}=1,517.34, p<.0001\right]$ than for primes in the $\operatorname{LVF}\left[F(1,24)=6.49, M S_{\mathrm{e}}=1,707.50\right.$, $p<.05]$. An analysis of the RT data for pseudoword targets showed a main effect of repetition $[F(1,24)=28.47$, $\left.M S_{\mathrm{e}}=1,186.96, p<.0001\right]$, no main effect of eccentricity $\left[F(6,144)=1.27, M S_{\mathrm{e}}=2,499.73, p>.1\right]$, and a reliable interaction $\left[F(6,144)=3.74, M S_{\mathrm{e}}=2,051.41, p<\right.$ $.005]$. There were no main effects and no interaction in the accuracy data for pseudowords $(F<1)$.

\section{GENERAL DISCUSSION}

In the present study, we investigated repetition priming effects, using the masked priming paradigm and varying the location of prime and target stimuli (Experiment 1A) or only prime stimuli (Experiments 1B and 2) along the horizontal meridian. Figure 4 summarizes the pattern of priming effects across these experiments. Priming effects systematically interacted with eccentricity, with the strongest priming appearing at the most central locations. Priming effects also tended to be more restricted with central targets and stronger for primes in the RVF than for those in the LVF.

The present study replicated the robust parafoveal priming effects found for peripheral and central targets in the seminal studies of Rayner and colleagues (Rayner et al., 1978; Rayner et al., 1980). In line with these studies, our results showed a similar pattern of priming effects for both peripheral targets (with prime and target at the same location) and central targets, although the size of the priming effects tended to be smaller in the latter condition. Most important, our experiments showed robust priming effects with peripheral primes and centrally located targets in conditions that severely limited prime visibility. This is evidence that location-invariant orthographic representations are responsible for at least part of these priming effects. Furthermore, in the present study, a similar pattern of priming effects was found for pseudoword targets (see Figure 4). This points to prelexical orthographic representations as a good candidate for achieving the location invariance reflected in our priming effects. The orthographic coding scheme proposed by Grainger and van Heuven (2003; see also Grainger, Granier, Farioli, van Assche, \& van Heuven, 2006) fits the bill. In this scheme, open-bigram representations detect the presence of a given sequence of letters independently of their location along the horizontal meridian.

These priming effects, obtained when primes and targets occupied distinct locations, would appear to contra- 


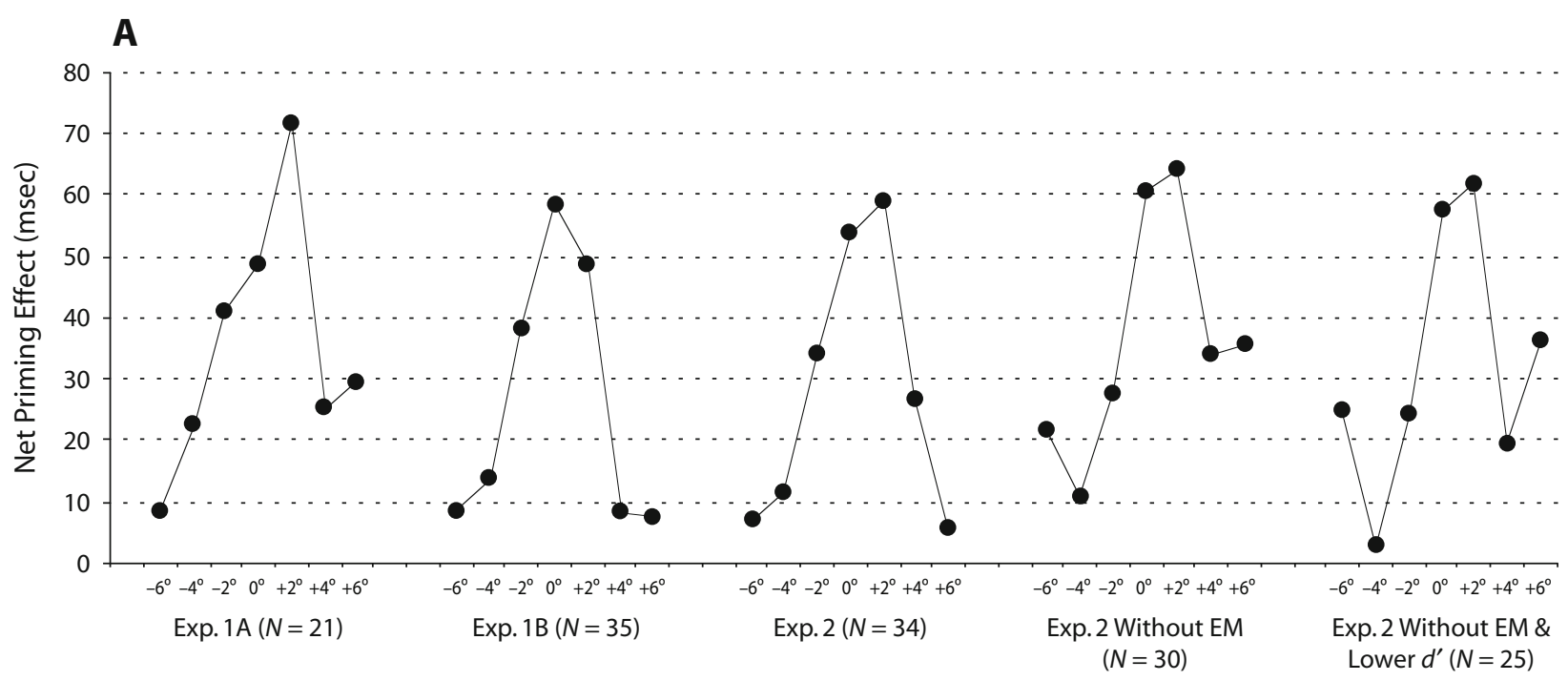

B

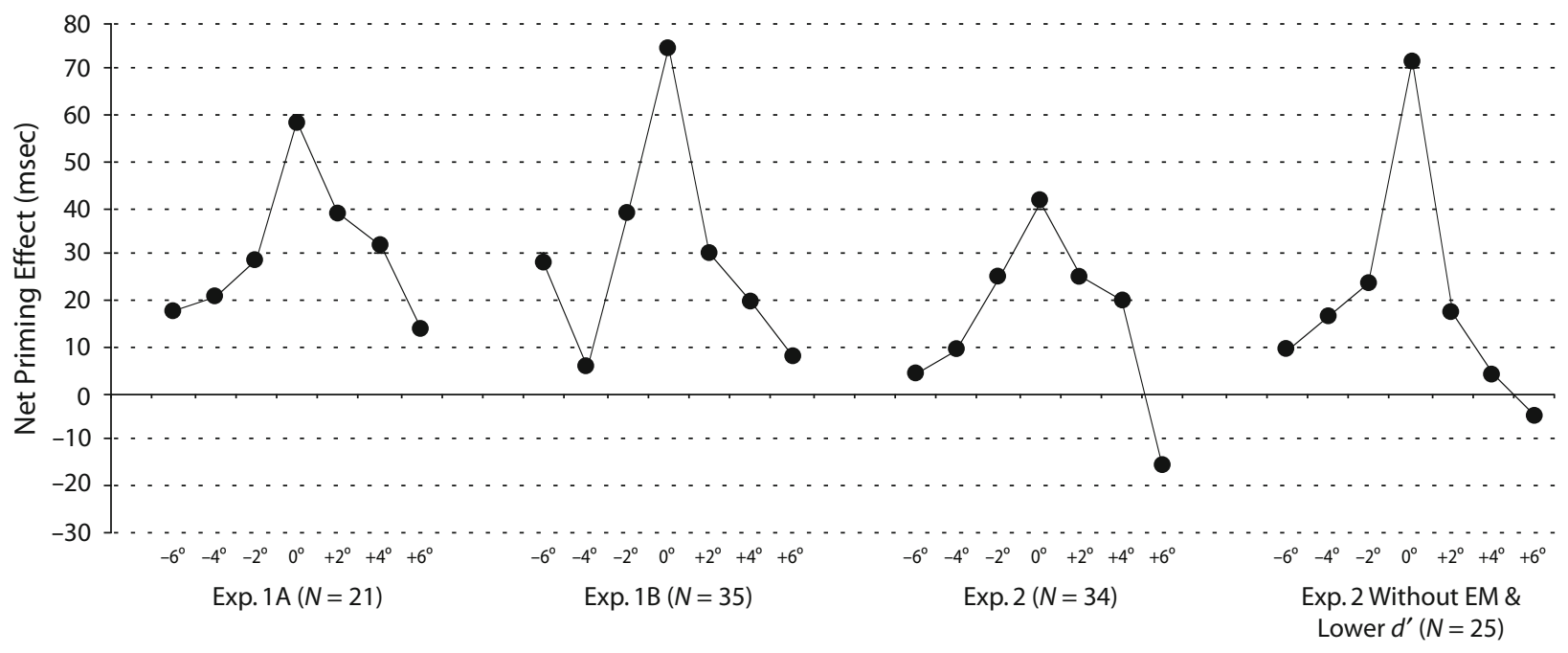

Figure 4. Priming effect sizes for word targets (A) and pseudoword targets (B) at each level of eccentricity in Experiment 1A, Experiment 1B, Experiment 2 with all trials, Experiment 2 after excluding trials with eye movements (EMs) and noncentral fixations, and Experiment 2 without eye movements and including only participants with the lowest $d^{\prime}$ values.

dict previous reports of an absence of masked repetition priming in such conditions (Besner et al., 2005; Lachter et al., 2004). In these studies, priming was found only in the presence of a valid exogenous cue that attracted attention to the prime location. However, one critical difference with respect to the present study is that prime location varied vertically in the previous work, as opposed to the horizontal manipulation used here. The account of location-invariant priming mentioned above is valid only for horizontal displacement of stimuli. Furthermore, our horizontal manipulation gave rise to a visual field asymmetry, so that priming effects were stronger for primes in the RVF than for primes in the LVF (after controlling for noncentral eye fixations in Experiment 2).

A similar RVF bias was reported by Marzouki et al. (2007) for isolated letter stimuli. Repetition priming for centrally located letter targets was greater when primes appeared to the right of fixation, relative to primes appearing to the left. Since priming effects were also affected by exogenous spatial cues in this study, a parsimonious explanation for these results is that attentional mechanisms underlie both the effects of spatial cuing and the effects of visual field. Therefore, the RVF advantage for priming effects in the present study could reflect an endogenous attentional bias toward the right for languages that are read from left to right (see Ducrot \& Grainger, 2007, for a review and recent evidence in favor of this position). This endogenous bias would improve the processing of prime stimuli appearing in the RVF, thus generating stronger priming effects in this condition. It would therefore appear that both exogenous and endogenous attention can influence the magnitude of masked repetition priming. 


\section{AUTHOR NOTE}

Y.M. was supported by a doctoral grant from the French Ministry of Education. The authors thank Stephane Dufau for his help in setting up Experiment 2 and Françoise Vitu for her help in analyzing the eye movement data in this experiment. Correspondence concerning this article should be addressed to Y. Marzouki, Laboratoire de Psychologie Cognitive, Université de Provence, 3 place Victor Hugo, 13331 Marseille, France (e-mail: yousri.marzouki@univ-provence.fr).

\section{REFERENCES}

Besner, D., Risko, E. F., \& Sklair, N. (2005). Spatial attention as a necessary preliminary to early processes in reading. Canadian Journal of Experimental Psychology, 59, 99-108.

Ducrot, S., \& Grainger, J. (2007). Deployment of spatial attention to words in central and peripheral vision. Perception \& Psychophysics, 69, 578-590

Forster, K. I., \& DAvis, C. (1984). Repetition priming and frequency attenuation in lexical access. Journal of Experimental Psychology: Learning, Memory, \& Cognition, 10, 680-698.

Forster, K. I., \& Forster, J. C. (2003). DMDX: A Windows display program with millisecond accuracy. Behavioral Research Methods, Instruments, \& Computers, 35, 116-124.

Grainger, J., Granier, J. P., Farioli, F., Van Assche, E., \& van Heuven, W. (2006). Letter position information and printed word per- ception: The relative-position priming constraint. Journal of Experimental Psychology: Human Perception \& Performance, 32, 865-884.

Grainger, J., \& VAN Heuven, W. (2003). Modeling letter position coding in printed word perception. In P. Bonin (Ed.), The mental lexicon (pp. 1-24). New York: Nova Science.

Lachter, J., Forster, K. I., \& RuthrufF, E. (2004). Forty-five years after Broadbent: Still no identification without attention. Psychological Review, 111, 880-913.

Marzouki, Y., Grainger, J., \& Theeuwes, J. (2007). Exogenous spatial cueing modulates subliminal masked priming. Acta Psychologica, 126, 34-45

Pollatsek, A., Lesch, M., Morris, R. K., \& Rayner, K. (1992). Phonological codes are used in integrating information across saccades in word identification in reading. Journal of Experimental Psychology: Human Perception \& Performance, 18, 148-162.

RAYNER, K. (1998). Eye movements in reading and information processing: 20 years of research. Psychological Bulletin, 124, 372-422.

RAYNER, K., MCCONKIE, G. W., \& EHRLICH, S. (1978). Eye movements and integrating information across fixations. Journal of Experimental Psychology: Human Perception \& Performance, 4, 529-544.

RaYNER, K., McConkie, G. W., \& Zola, D. (1980). Integrating information across eye movements. Cognitive Psychology, 12, 206-226.

(Manuscript received September 28, 2006; revision accepted for publication July 3, 2007.) 